\title{
Solar Cooling - A Green Energy Solution for Reducing Food Losses
}

\author{
Vanniarachchy M.P.G.*, Bamunuarachchi A. \\ Department of Food Science \& Technology, University of Sri Jayewardenepura, Sri Lanka \\ *mihiripg@gmail.com
}

\begin{abstract}
According to the recent reports of the Food and Agriculture Organization (FAO) of the United Nations, roughly one third of the food produced in the world for human consumption every year get lost or wasted globally, while 800 million people are going into hungry. Saving $1 / 4$ of the food which is been wasted will provide the opportunity to feed this 800 million people. Food waste refers in to throwing perfectly edible food into trash at the consumption level while food loss refers to the losses which occur along the food chain that is at the production, harvesting, post-harvest activities and processing phases. Poor handling transport, storage facilities and lack of correct infrastructure cause post-harvest food losses in developing countries. Fresh products like fruits, vegetables, meat and fish straight from the farm or after the harvest can be spoilt in hot climates due to lack of infrastructure for correct transportation, storage, cooling and marketing. Sri Lankan scenario is not much different to the rest of the world where there is about $10-40 \%$ loss in fruits and vegetables within food supply chain. There are no country wide valid estimates of looses among other food commodities. Sri Lanka located close to the equator, receives an abundant supply of solar radiation throughout the year. Solar radiation over the island does not show a marked seasonal variation. Due to these reasons, solar cooling is a promising technology to address reducing food losses in Sri Lanka. Solar cooling technology can be applied for food preservation by using it to generate ice or for refrigeration. Different types of ice (blocks or flakes) are typically used to keep fish or milk within the conservation temperature range. These types of ice making facilities are globally available and managed by a community or a cooperative. Solar refrigerators are used for the purpose of conserving fruits and vegetables which operates at a temperature below $10^{0} \mathrm{C}$. There are many solar refrigeration technologies available such as well known solar photovoltaic systems, solar absorption systems and, solar adsorption systems. Each of these technologies have their own advantages and limitations and most of these technologies are still at the developing stage. There is a global trend towards harnessing solar energy for food preservation and this will be a promising technology to reduce food losses in Sri Lanka.
\end{abstract}

Keywords: Solar cooling, Solar refrigeration, Food losses

Proceedings of the $22^{\text {nd }}$ International Forestry and Environment Symposium 2017 of the Department of Forestry and Environmental Science, University of Sri Jayewardenepura, Sri Lanka 